\section{Problems of European law}

SIR - Although 1992 should mark the establishment of a free market of individuals, goods and services in the countries of the European Communities and the European Free Trade Association (EFTA), there remain limitations on the movement of people (in this case a scientist) that should have been abandoned long ago. Instead, these limitations are enforced by recent laws.

I work at the National Cancer Institute in Milan, Italy. Having funds for a postdoctoral fellow, I advertised in $\mathrm{Na}$ ture and received nine applications for this position, none of them from an Italian national. The most suitable candidate was a Chinese scientist (Z.Y.) who had been living in Switzerland since 1989 and who recently (February 1992) got his $\mathrm{PhD}$ in pharmacy from the University of Bern. I therefore invited him to Milan for an interview. At this point, the nightmare materialized. As he was Chinese, he needed a visa to enter Italy. A new Italian immigration law requires a minimum of three months valid residence permit in the country of residence before a visa can be issued. Z.Y. had only two months of validity (his visa in Switzerland was linked to his position as a PhD student) and was therefore not eligible for even a one-day visa. I called the Italian consulate in Bern, but nobody would take responsibility for granting the visa. My letter of invitation or my oath that Z.Y. would return to Switzerland after the interview made no difference. I was even offered friendly advice to hire an Italian national.

With an Italian sense of realism, I arranged to hold the interview in Chiasso (Switzerland), $40 \mathrm{~km}$ from Milan. I and another representative of my institution met Z.Y. in Chiasso and we decided that he was the right person for the position. However, my institution required that Z.Y. be physically present in Milan for at least one day before an official appointment as postdoctoral fellow could be made. But, because of the law, Z.Y. could not visit Milan, so he could not be appointed to the fellowship. Because he could not be appointed, he could not apply for a visa to reside in Italy. To make things even worse, Z.Y. was refused an extension of his residence permit in Switzerland.

The conclusion was that I lost the best candidate for this position; Z.Y. was forced to go back to China; and I wasted at least four days of my time in this fruitless attempt.

Although the general effect on illegal immigration of this new law is clear to everybody in Milan (at almost every traffic light there is an immigrant trying to wash one's windscreen), the law has efficiently blocked the legal immigration of a skilled scientist who was needed for a position in Italy.

I have also come to realize that each EC and EFTA country has its own different immigration law and that Z.Y., for example, could have gone to France with little difficulty, although he could not enter Italy. This situation is not only unproductive and unacceptable, but also underlines the huge difficulties that still lie (nine months from the unitary market of 1993) between us and a truly United Europe. For some people, the trip from Bern to Milan (about $300 \mathrm{~km}$ ) is still full of hidden dangers in 1992.

Via Lissoni 5,

20052 Monza, Italy

\section{Productivity drive}

SIR - In a recent study on prolific productivity among prominent scientists (Medical Hypotheses, in the press), I have identified eight scientists who have been authors of more than 1,000 research publications, including books, monographs and patents as well as regular papers. They are, in chronological order, Thomas Alva Edison, Paul Karrer, Margaret Mead, Giulio Natta, Hans Selye, Herbert C. Brown, Tetsuji Kametani and Carl Djerassi. Among these, Karrer, Natta and Brown were Nobel prizewinners in chemistry. Four criteria that I was able to identify as clues to their prolific productivity are (1) enthusiasm for compulsive work and eccentric life style, (2) physical and/or environmental handicap, (3) pioneering efforts in a new research field and (4) selection of research area, predominantly organic chemistry. If one takes into account the publications of scientists on social and political issues as well, I believe that Bertrand Russell and Linus Pauling (both Nobel prizewinners) also share the credit for prolific productivity, lasting for seven decades.

Osaka BioScience Institute,

SACHr SRi KanTHA

6-2-4 Furuedai, Suita,

Osaka 565, Japan

\section{'Neutral' CFCs?}

SIR - The suggestion ${ }^{1}$ that CFCs may be 'greenhouse neutral' on a global scale may bear on the negotiations at Rio de Janeiro in June aimed at reducing the potential for global warming.

Although spatial variations of ozone concentration will complicate the argument ${ }^{2}$, at first sight the possibility of neutrality diminishes the credibility of the Bush Administration's position that CFC emissions should be traded off against carbon dioxide emissions in a comprehensive approach ${ }^{3}$. In any case, this development indicates the difficulties that might arise as a result of changing knowledge if such an approach was adopted ${ }^{4}$, and should serve as a warning that the question of carbon dioxide reductions cannot be avoided.

The result also challenges the administration's view that global change research has 'matured' and requires less funding for basic research ${ }^{5}$

KEITH MONTGOMERY

Department of Geography-Geology,

University of Wisconsin -

Marathon Center,

518 South 7th Avenue,

Wausau, Wisconsin 54401, USA

1. Ramaswamy, V., Schwarzkopf, M. D. \& Shine, K. P. Nature 355, 810-812 (1992)

2. Kiehl, J. T. Nature 355, 773 (1992),

3. US Task Force on the Comprehensive Approach to Climate Change. A comprehensive approach to addres sing potential climate change. (US Department of Justice, Washington DC, 1991)

4. Grubb, M. J., Victor, D. G. \& Hope. C. W. Nature 354 348-350 (1991)

5. Mervis, J. Nature 355. 578 (1992).

\section{Gene patents}

SIR - Craig Venter and colleagues recently expanded their original list of expressed sequence tags (ESTs) ${ }^{1}$ to include an additional 2,375 sequences from human brain cDNA libraries ${ }^{2}$. The appropriateness of obtaining patents on these sequences has generated well publicized controversy. Not so readily publicized is that in at least eight cases the Venter group appears to be applying for patents on sequences from the Bluescript sequencing vectors. I believe that Stratagene ${ }^{3}$, the owner of these popular vectors, may be likely to object to the award of patents to the Venter group for these sequences.

A search of the Genbank database ${ }^{4}$ that I conducted shows the following ESTs to contain Bluescript polylinker sequences: Est02006, Est01040, Est01016, Est01479, Est00328, Est02460. In addition, the following ESTs contain vector sequences which flank the polylinker: Est01431 and Est01430. The fact that these entries contain vector sequences may be indicative of the degree of analysis to which they have been subjected. Furthermore, it may shed light on the general advisability of obtaining patents on the entire set of EST sequences without further analysis of the individual sequences.

JONATHAN MARC ROTHBERG Howard Hughes Medical Institute, Boyer Center for Molecular Medicine, Yale University School of Medicine, New Haven, Connecticut 06536, USA

1. Adams, M. D. et al., Science 252, 1651-1656 (1991). 2. Adams, M. D. et al., Nature 355, 632-634 (1992).

3. Stratagene Cloning Systems, La Jolla, California 92037

4. Aitschul, S. F. et al., J. molec. Biol.215, 403-410 (1990).

NATURE · VOL $356 \cdot 30$ APRIL 1992 